\title{
Health issues for the 21st century: infection, antimicrobial drug resistance, distance learning and technology
}

Despite many reservations, 20th century Western civilisation will greet the new millennium with a sense of achievement, much of it attributed to technological and scientific advance. The benefits of such achievements are nowhere more obvious or more welcome than in medical science. However, disquiet is growing.

The speed and volume of change (often confused with progress) have outstripped our ability to keep abreast of developments and their implications, even within increasingly narrow specialties. There is little time, or incentive, to keep a broader view, to put specialised work in perspective, to promote collaboration (and real progress) among partners involved in different parts of a bigger whole - e.g., identification and management of international health concerns such as the control of infectious diseases and antimicrobial drug resistance [1]. Unnecessary jargon further impedes communication. Health services worldwide face widening gaps between expectation and outcome (professional and public); between equal rights accorded by law and the equality of care deliverable in practice.

'Education', 'training' and 'access' are offered as solutions for many such dilemmas. Technology is often the 'innovative' focus of the solutions offered. Alone, it is not the answer [2]. Neither is 'education' just a matter of presenting facts [3]. Without relevance and re-inforcement, facts rarely change behaviour or maintain beneficial change. As interest in computerassisted education mushrooms, we need to take more than rhetorical stock of our relationship with technology and its role in education, to look beneath undoubted assets and ask:

Have we become too dependent on and demanding of the concept? Do we take the many applications, speed and ease of use for granted - nowhere more so than in medicine and education [4-6]? Do we use technology as a director of operations rather than as a powerful facilitator and messenger - an emphasis that replaces, rather than complements, fundamental skills and wisdom based on experience? In an age where 'enabling' and 'empowerment' are emphasised, is technology 'disabling' us - demeaning past achievements and practice, blunting fundamental ways of thinking needed for problem solving, communication and planning? Are we in danger of unravelling 'progress' and leaving potentially destructive 'change' in its place - as in antimicrobial drug resistance? In short, have we created an environment, not only in medicine, where unrealistic expectations of technology set unrealistic goals: goals unattainable by the most able and committed personnel - especially within the time or resources allocated for the task?

A quick return to the early 1900 s - without rose-tinted spectacles! - helps put technology and 'innovation' in perspective. Medical science flourished, propelled by the impetus of the Industrial Revolution. The research laboratory became a cornerstone of scientific advance. Models for modern laboratory services sprinted from infancy to adolescence as scientists used 'new technology' and developed 'evidence-based', 'problem-solving' 'scientific method' to explore links between the mystical world of microbes and visible disease. Meticulous observation and recording, review, reflection and revision formed the building blocks which brought success and set down standard guidelines for professional research and practice. Specialisation had not yet distanced the roles of technician and artist from scientist and clinician. Academic research fed directly into clinical programmes - often in remote places [7]. In 1902, Ross won the Nobel Prize for linking the anopheles mosquito to malaria transmission. His hand-drawn illustrations provide much food for thought.

Early pioneers, like their modern colleagues, strove to stimulate professional awareness of, interest and competence in, and financial support for their projects. They sought professional recognition and prestige. They disseminated their work and studied by complementary methods - publication, demonstration, display and discussion. Competition was fierce but mostly manageable - the power of the media and an aware public lurked on the horizon. The economic significance of 'the health of the nation' emerged and global perspectives attracted attention. Henry Wellcome, for example, convinced of a close relationship between tropical disease and international health, brought specimens of important diseases to his museums in London. He selected his topics and materials carefully for a target audience of international, medical and life science students and teachers. English was often not their first language. He combined visual images with clear, concise texts to deliver complex messages across language and profes- 
sional barriers. The Wellcome Museum for Medical Science served its visitors well for over 50 years.

The Wellcome Tropical Medicine Resource (TMR) [8], the computer-based visual archive and interactive tutorials which replaced the museum, addresses the same topics (major issues in tropical and international health), uses the same principles, and targets the same audiences. Technology has modified presentation and extended access. It needs constant, skilled support. In April 1995, TMR's first MS-DOS based CD-ROMs (including packages dealing with malaria, schistosomiasis, trachoma and sexually transmitted diseases) were appraised by centres of learning in 19 countries. A revised, extended version, now under review in over 80 centres worldwide, is contributing to programmes as far apart as the UK, Africa, Brazil, Australia and China. Windows-based, cross platform versions, which will reflect analysis of the review results, will appear in 1997.

TMR, like many computer-based resources, represents a logical extension and modern expression of welltried principles and practices long used to good effect in education, publishing and advertising. They underlie the colourful presentations seen on TMR's videodisc and CD-ROM and in the prototype tutorial on World Wide Web (Trachoma: clinical signs and grading. http://www.chime.ucl.ac.uk/TMR/Trachoma). They have influenced TMR's editorial and operational guidelines, which promote consistent styles, quality control and efficient time management. Coping with 'change' (including international legislation affecting copyright and intellectual property) has been incorporated into TMR's basic planning/design protocols: the contents may be easily updated or modified for use with new technology. TMR offers an option among reliable sources and forms of information.

Technology (the messenger) facilitates TMR presentation and delivery. Subject experts work with trained TMR staff to create and maintain the contents (the message). Technologists and academics must work together and, most important, with their target audiences to develop and maintain worthwhile products. TMR participates with users in an ongoing appraisal of the materials, noting topic priorities and technology used or planned. Focus, TMR's twice yearly international news bulletin, launched last November, will facilitate communication.

TMR plans to highlight antimicrobial drug resistance and related issues in its interactive tutorials, e.g., on tuberculosis and sexually transmitted diseases. Practical guidelines for laboratory use (e.g., tests and techniques best for 'gold standard' and field locations) and benefits of co-operation between technicians and clinicians will be described.

The advent of penicillin in 1944 suggested the defeat of infection. Within a few years resistant Staphylococcus aureus burst the euphoric bubble. There was a gradual realisation that medical students need to learn about the process and dangers of antimicrobial drug resistance: of the influence of factors such as good prescribing and individualised therapeutic regimens, of patient compliance and over-the-counter, multiple selfmedication, of effective use of laboratory services and of doctor/patient relationships.

Forty years on, resilient, 'changed' and 'changing' micro-organisms pose an ominous challenge for the new millennium. They threaten to unravel progress made against major infections and preventable, premature death and morbidity worldwide. The problem reflects failure to address the many aspects of resistance with the long-term rigour and co-operation required, nationally and internationally, within and among the health professions, pharmaceutical industry and government departments. Technology and distance learning alone cannot solve such problems. However, devised and supported wisely, they will provide a powerful ally for the skilled individuals and multinational teams who must take the lead. Failure is not an option [9].

Dr R. YOUNG Tropical Medicine Resource, The Wellcome Centre for Medical Science, 210 Euston Road, London NW1 2BE.

\section{References}

1. Kunin CM. Resistance to antimicrobial drugs - a worldwide calamity. Ann Intern Med 1993; 118: 557-561.

2. Coiera E. Medical Informatics. BMJ 1995; 310: 1381-1387.

3. Bulstrode $C$, Holsgrove $G$. Education for educating surgeons. Time for a professional approach. BMJ 1996; 312: 326-327.

4. Waugh RA, Mayer JW, Ewy GA, et al. Multimedia computerassisted instruction in cardiology. Arch Intern Med 1995; 155: 197-203.

5. Duguid KP. The team approach to the design of computerassisted learning packages in medicine. J Audiov Media Med 1995; 18: $53-58$.

6. Edwards J. Judging the usefulness of courseware. J Audiov Media Med 1995; 18: 83-84.

7. James RR. Henry Wellcome. London, Hodder and Stoughton. 1994.

8. Young RAC. The Wellcome Tropical Medicine Resource: 19th century principles, 21 st century technology, and distance learning with global horizons. Trans $R$ Soc Trop Med Hyg 1995; 89: $465-466$.

9. Klaudt K [Ed]. Stop TB at the source: the WHO report on the tuberculosis epidemic 1995. WHO, Geneva. 